\title{
El Espańol como Lengua Extranjera (e/le): en búsqueda de la adquisición de una voz identitaria
}

\author{
Cleidimar Aparecida Mendonça e Silva* \\ Lucielena Mendonça de Lima**
}

\section{Resumen}

Este trabajo discute los datos generados en una sesión reflexiva realizada con las alumnas del último año de la licenciatura en Letras/Español, de la Faculdade de Letras da Universidade Federal de Goiás (UFG). Las futuras profesoras consideran si han adquirido, a lo largo de su formación académica, una voz propia, es decir, una identidad lingüística en dicha lengua. Asimismo, evalúan las variables que puedan haber contribuido para la constitución de esa identidad: los profesores nativos o brasileños, los materiales didácticos y auténticos utilizados, los cursos específicos de formación, los contactos con nativos, entre otros factores. Sabemos que el término "identidad", bastante polémico, de difícil conceptualización, unas veces aceptado, otras rechazado, siempre ha estado en la pauta de discusión de las ciencias sociales, humanas y también de la filosofía. Por ello, nos proponemos investigar el estado de la cuestión respecto a ese tema abordando sus conceptos principales, las cuestiones relacionadas con los procesos identitarios en la actualidad y su relación con la enseñanza-aprendizaje del espańol como lengua extranjera (E/LE). Los datos recogidos en la sesión seńalan para una identidad, fruto de la influencia de un sinnúmero de factores, aún en proceso de adquisición por parte de las futuras profesoras de espańol.

Palabras clave: espańol/lengua extranjera, identidad lingüística, voz propia.

O Espanhol como Língua Estrangeira (e/le): em busca da aquisição de uma voz identitária

\section{Resumo}

Este trabalho discute os dados gerados em uma sessão reflexiva realizada com as concluintes da graduação em Letras/Espanhol, da Faculdade de Letras da Universidade Federal de Goiás (UFG). As futuras professoras consideram se adquiriram, ao longo de sua formação acadê-

* Profesora del Área de Español de la Faculdade de Letras da Universidade Federal de Goiás (Doctoranda del Programa de Pós-Graduação em Letras e Linguística de la FL/UFG. E-mail <profcleidemendonca@bol.com.br>

** Profesora del Área de Español de la Faculdade de Letras da Universidade Federal de Goiás y del Programa de Pós-Graduação em Letras e Linguística de la FL/UFG. E-mail <llima@letras.ufg.br> 
mica, uma voz própria, isto é, uma nova identidade linguística na referida língua. Avaliam, também, as variáveis que podem ter contribuído para a constituição dessa identidade: os professores nativos ou brasileiros, os materiais didáticos e autênticos utilizados, os cursos específicos de formação, os contatos com nativos, entre outros fatores. Sabemos que o termo "identidade", bastante polêmico, de difícil conceituação, umas vezes aceito, outras rechaçado, sempre esteve na pauta de discussōes das ciências sociais, humanas e também da filosofia. Por isso, nos propusemos a investigar o estado da questáo a respeito desse tema abordando seus conceitos principais, as questóes relacionadas com os processos identitários na atualidade e sua relação com o ensino-aprendizagem do espanhol como língua estrangeira (E/LE). Os dados coletados na sessão apontam para uma identidade, fruto da influência de inúmeros fatores, ainda em processo de aquisiçáo pelas futuras professoras de espanhol.

Palavras-chave: espanhol/ língua estrangeira, identidade linguística, voz própria.

Spanish as a Foreign Language $(\mathrm{s} / \mathrm{fl})$ : searching for the acquisition of an identity voice

\begin{abstract}
This paper discusses the data which were produced throughout a reflective session with the undergraduates of Spanish Graduation Course from Faculdade de Letras, Universidade Federal de Goiás (UFG). According to the students' opinions, they have acquired their own voices in Spanish as well as a linguistic identity in this language during their academic lives at university. The students under investigation also evaluate the variables which might have contributed to the constitution of their identities: their professors, the Brazilian ones and the Spanish speaking ones, the didactic materials, courses in Second Language Teacher Education, interactions with native speakers of Spanish and other factors. We know that the word identity is pretty polemical and is not easily conceptualized, sometimes it is accepted or criticized, and it has always been discussed by Philosophy, Social and Human Sciences. For this reason, we have aimed to raise discussions on this subject matter and its main concepts, especially the topics concerning the current identity processes and their relationships with the teaching and learning processes of Spanish as a foreign language (S/FL). The data collected point out to an identity which is the result of several factors and their influences, and it is still being acquired by the future Spanish teachers.
\end{abstract}

Keywords: Spanish/Foreign language, linguistic identity, one's own voice.

\title{
Introducción
}

En nuestro contexto de formación universitaria de los futuros profesores de español como Lengua Extranjera (E/LE) en la UFG, la cuestión identitaria juega un papel importante puesto que los sujetos aprendientes se hallan posicionados constantemente entre dos lenguas "moderamente próximas” (Kulikowski; González, 1999): el portugués brasileño y el espa- 
ñol. Con ésta última lengua la relación es formal y metalingüística y se limita casi que exclusivamente al ámbito del aula ya que el Estado de Goiás está ubicado en el Centro-Oeste de Brasil, espacio geográfico alejado de las regiones de fronteras con los países hispanoamericanos y en nuestra capital se registra una presencia poco significativa de nativos hispanófonos. Las estudiantes de Letras también se estaban formando doblemente como hablantes-usuarias, ya que su primer contacto con el idioma ocurrió en la universidad, y como profesionales de español, una lengua que Celada (2002) interpreta como "singularmente extranjera" para el brasileño. Eso equivale a decir que, en un primer momento, la creencia generalizada en la presunta facilidad del idioma, fruto de las muchas, pero relativas, similitudes con el portugués brasileño, genera la ilusión de competencia espontánea, el portuñol, una especie de extensión de nuestra Lengua Materna (LM), como bien explica la autora.

Sin embargo, el estudio profundizado del idioma, justamente porque estamos formando al futuro profesor de español, pone de manifiesto las idiosincrasias de su sistema lingüístico y revela sus nuevas discursividades, no tan parecidas con la LM como se esperaba, hecho que le da al discente la sensación de frustración por no poder "dominarla" con la facilidad inicialmente imaginada. Como consecuencia, pasa a sentir que su producción lingüística no avanza como debería y se halla en el medio del camino, es decir, en un estadio de interlengua (IL) que se caracteriza por avances y retrocesos de acuerdo con la historia y las experiencias educativas de cada uno, como postulan las Orientaçóes Curriculares para o Ensino Médio - Espanhol (OCEM, 2006), documento que presenta directrices para la enseñanza ${ }^{1}$ de ese idioma en Brasil.

Ante lo expuesto, creemos que desarrollar una nueva identidad lingüística en español, adquirir una voz propia que lo identifique al sujeto, ya constituido en su LM, como hablante pleno de la LE, es algo extremadamente complejo. Estamos considerando, en el ámbito de este trabajo, que poseer una voz identitaria significa el individuo proyectarse, posicionarse y expresarse, en distintas situaciones, de forma a sentirse seguro, expresando adecuamente todo lo que necesita, buscando revelar "quem é o eu que fala estrangeiro" (Revuz, 2002, p. 224). Para ello, discutimos los conceptos y los principios teóricos de la identidad según la Lingüística Aplicada (LA) y los Estudios Culturales. 
Con el objetivo de detectar si las futuras profesoras de español consideraban que habían desarrollado una identidad lingüística en esa lengua, se propuso una sesión reflexiva de una hora y media de duración al final del último período de la carrera de Letras. En ese evento fue posible realizar una discusión sobre las siguientes dos preguntas:

- ¿Crees qué ya tienes "voz en lengua española", es decir, consideras qué ya posees una identidad lingüística en esa lengua?

- En caso negativo, ¿qué te falta todavía?

Esperamos que este texto sirva como reflexión inicial para la discusión y problematización de este tema tan complejo y desafiador, como es la cuestión identitaria relacionada con el proceso de formación universitaria del futuro profesor de E/LE. En esos términos, y en los límites de este artículo, es importante preguntar: quiénes somos, qué identidades poseemos en la LM, qué identidad(es) construimos en la LE y cómo proyectamos nuestra voz en la nueva lengua.

\section{La Identidad en la Perspectiva de los Estudios Culturales}

La conexión entre lengua e identidad se hace importante especialmente en nuestra sociedad contemporánea globalizada, donde las fronteras entre culturas y personas están cada día más estrechas, debido a los constantes contactos comunicativos físicos y virtuales. En ese sentido, el reto principal que se debe buscar en el proceso de formación universitaria del futuro profesor de E/LE es el desarrollo de una postura educativa intercultural. Eso significa que el contacto con el otro, con su lengua, con sus manifestaciones culturales, con su modo de percibir el mundo y con sus identidades, debe posibilitar al sujeto de la LM reconocerse a sí mismo como un individuo múltiple y complejo en una sociedad local que así también lo es. Esa postura educativa también la defienden las OCEM (2006, p. 129) que considera que exponerle al alumno: "à alteridade, à diversidade, à heterogeneidade, [é um] caminho fértil para a construção da sua identidade".

Según Hall (2005), se pueden explicar tres concepciones de identidad: 1) la del sujeto del Iluminismo; 2) la del sujeto sociológico y 3) la del sujeto posmoderno. La primera se caracteriza por considerar el sujeto como un individuo centrado, unificado, racional y consciente. Así, su identidad es 
homogénea, fija, total y estable. La segunda concepción es la de identidad interactiva y el sujeto está en relación con otras personas o grupos sociales. Esta concepción, a pesar de no ser fija, trae la idea de unidad, además de cierta estabilidad por hacer un puente entre espacio interior ("yo real") y exterior ("mundos culturales"). En la tercera concepción se ve la identidad como móvil, múltiple y contradictoria. En esta perspectiva, Souza (2007) aclara que en la posmodernidad el sujeto se considera a partir de la fragmentación, del desplazamiento y del descentramiento, por eso la identidad es híbrida y constituida en y por la alteridad. Dicho concepto nos interesa especialmente en este texto puesto que en nuestra realidad de formación del futuro docente brasileño de E/LE, sabemos que adoptar una nueva posición identitaria en la lengua meta es algo conflictuoso, ya que, involucra la utilización de nuevas formas de enunciar, nuevas discursividades que a veces pueden desestabilizar la subjetividad ya constituida en la LM.

En ese escenario, no hay como no considerar que se opera un desplazimiento en el sujeto aprendiente que ora se refugia en la seguridad que le ofrece su LM, y con eso sufre los efectos de la IL, ora se aventura en búsqueda de la expresividad propia de la LE. En ese sentido, Hall (2000, p. 103) explica que "as perspectivas que teorizam o pós-modernismo têm celebrado, por sua vez, a existência de um 'eu' inevitavelmente performativo". Tal postura se explica porque las posiciones de sujetos que asumimos son reveladas por nuestras acciones y actitudes. Así, Butler (1999) adopta la posición de que el sujeto es discursivamente construido y de que no existe ningún sujeto antes o fuera de la Ley (normas que regulan la sociedad). Y Silva (2000, p. 96-97) ratifica: "[...] a identidade é uma construção, um efeito, um processo de produção, uma relação, um ato performativo. A identidade é inestável, contraditória, fragmentada, inconsistente, inacabada”. De esa forma, aprender una nueva lengua con el reto de poder enseñarla a otros sujetos es un proceso que cuestiona las múltiples identidades que poseemos en la LM y que inevitablemente se ven desplazadas ante las nuevas formas de decir en la LE.

Woodward (2000) presenta una clasificación de los estudios identitarios en dos categorías: la esencialista - en la cual la identidad es cristalina, auténtica y fija, es decir, se trata de la primera concepción de identidad presentada anteriormente por Hall (2005) y la no-esencialista - marcada por diferencias, mutación y fluidez (la perspectiva posmoderna de los Estudios Culturales). De esa forma, la autora muestra que la 
identidad está dividida en: 1) biológica (división entre hombres y mujeres, visión esencialista); 2) cultural (no-esencialista, involucrando los aspectos global, nacional, local y personal) y 3) histórica (propuesta por Judith Butler al discutir cuestiones complejas involucrando al sujeto, el cuerpo y la identidad en perspectivas foucaultianas y psicoanalíticas). Considerando esos aspectos, la autora postula que "a cultura molda a identidade ao dar sentido à experiencia e ao tornar possível optar, entre as várias identidades possíveis, por um modo específico de subjetividade" (Woodward, 2000, p. 18-19). En nuestro proceso de formación universitaria del futuro profesor de español en Brasil, el conflicto identitario también se puede instaurar debido a la dificultad de interpretar esas múltiples identidades extranjeras, fruto de pautas histórico-ideológicoculturales desconocidas.

Por eso, Souza (2007) argumenta que en la modernidad tardia (Giddens, 1991), se considera que la identidad es "ilusoria" puesto que hay una "ilusión de unidad". De ahí que en lugar de usar el término "identidad", que trae la idea de unidad y totalidad, se prefiere el término identificación o procesos identitarios, que caracterizan la no estabilidad o movilidad, es decir, sugiere la idea de constante movimento. Woodward (2000, p. 18) comprende que la identificación es un concepto que describe "o processo pelo qual nos identificamos com os outros, seja pela ausência de uma consciência da diferença ou da separação, seja como resultado de supostas similaridades, tem sua origem na psicanálise”. Y Hall (2000) sintetiza que la identificación es una construcción, un proceso que no se completa jamás, como algo siempre en "proceso". En el caso de las futuras profesoras de E/ LE que formaron parte de esta investigación, la necesidad que destacaron de continuar estudiando después de concluir la carrera, demuestra que esa preocupación en seguir identificándose con la LE no ha terminado. En esa perspectiva, Silva (2000) establece una relación importante entre identidad y diferencia, ambas como productos del lenguaje. En nuestro contexto, el sujeto aprendiz puede darse cuenta de quién es al entrar en contacto con el otro de la LE y enterarse de las diferencias que lo caracterizan. Para el autor, identidad y diferencia involucran relaciones de poder y no son entidades preexistentes, sino que deben ser constantemente creadas y recreadas, principalmente si pensamos en la educación y en las cuestiones culturales, como pasamos a discutir a seguir. 


\section{Identidad, LM y Enseñanza/Aprendizaje del E/Le}

Nuestra LM nos constituye como sujetos mucho antes de nuestro nacimiento. Al saber que esperan un bebé, los padres y toda la familia ya inician el proceso de "decir" quién será el niño. Si chico o chica, colores, gustos, preferencias y aptitudes ya se seńalan y esperan. Y con la audición, primera y más eficaz fuente de contacto con el bebé, se van revelando diversos sonidos y entre ellos los fonos de la LM que sonarán como naturales, cargados de afecto e identificación para el futuro hablante.

De ese modo, Revuz (2002, p. 218-219) nos aclara que,

[c]ada um que se ocupa da criança fala dela, coloca em palavras o que percebe dela, de seu 'jeito de ser', de suas semelhanças, de suas necessidades. E essas falas são em todo momento interpretaçôes daquilo que é ou sente a criança, predicação sobre o que ela é, o que se espera dela, e nomeação das sensaçóes, dos afetos, dos objetos do mundo [...]. Assim, muito tempo antes de poder falar, a criança é falada intensamente pelo seu ambiente [...].

Ese intenso y singular proceso de subjetivación en la LM nos hace mantener con ella un vínculo estrecho y duradero, imposible de ser ignorado en los procesos de enseńanza-aprendizaje del E/LE (OCEM, 2006). Así, una de las importantes críticas que este documento hace al enfoque comunicativo es la reducción de la lengua a una única función, ser vehículo de comunicación. Al negar el estructuralismo lingüístico y afirmar el comunicativismo radical, muchas veces se presentan en el aula situaciones comunicativas artificiales, totalmente desprovistas de significación para la vida, las experiencias previas, los objetivos, las necesidades y la realidad del sujeto aprendiente. Ese hecho no considera que "mais do que aprender o código e suas funçóes na outra língua, o falante toma outra posição subjetiva [...] essa posição diz respeito a uma intersubjetividade inconsciente, que póe em jogo as contradiçóes da constituição histórica dos sujeitos" (Neves, 2006, p. 45).

De ahí que, en el proceso de aprendizaje de una LE, principalmente en la fase adulta, el sentimiento al expresarse en la nueva lengua es completamente diferente al de la lengua materna. No fuimos dichos en la LE por nadie, ni por el ambiente, no tenemos una estructuracción subjetiva en la misma, no poseemos, aún, vínculos afectivos y sólidos con ella. Así, 
acabamos regresando al estadio del bebé que debe (re)hacer el camino para hacerse entender, para expresarse con exactitud, para buscar nuevas posiciones subjetivas. De esa forma, aprender otra lengua es un proceso que "vem perturbar, questionar, modificar aquilo que está inscrito em nós com as palavras [da] primeira língua” (Revuz, 2002, p. 217).

En esa perspectiva, se mezclan miedo, agobio y ansiedad, pues Serrani-Infante (1998) cree que el encuentro con segundas lenguas probablemente sea una de las experiencias más visiblemente movilizadoras de cuestiones identitarias en el sujeto. Y en el caso del aprendizaje del E/LE en Brasil, hay siempre el aspecto de la similitud con el portugués brasileño, el deseo de comparar y contrastar formas, una herencia de las investigaciones que dominaron el escenario educativo hasta los años 80 del pasado siglo (OCEM, 2006). Eso genera frecuentemente una inseguridad en el hablante brasileño de español que tiene la impresión de estar siempre en un nivel de interlengua, por no encontrar "la justa medida de una cercanía", en las palabras de Kulikowski y González (1999, p. 11). De esa forma, Coracini (2003, p. 1516) hace hincapié en que,

[somos] sujeitos em travessia entre a nossa língua que chamamos de materna e a língua do outro que chamamos de estrangeira; esta nos questiona o tempo todo, interroga-nos naquilo que temos (ainda que ilusoriamente) de mais seguro: nossa própria identidade, que se vê, no outro e pelo outro, abalada, posta em xeque, desestabilizada.

Como reflexión final, Revuz (2002) nos explica que la LE va a confrontar al aprendiz con otro recorte de lo real, pero, sobre todo, con un recorte en unidades de significación desprovistas de su carga afectiva. Ese hecho seguramente desestabilizará y deslocará al sujeto de la LM que tendrá que buscar en la LE nuevas formas de enunciar, como nos explican Celada y Rodrigues (2005, p. 8):

[s]e ve el proceso de aprendizaje como un proceso de extrañamiento y de identificación, y por lo tanto como un espacio de subjetivación (de hacerse sujeto): someterse a otra lengua es ocupar nuevas posiciones del decir, desplazarse a partir de las "naturalmente" ocupadas en el ámbito de la materna. Por eso, el proceso de enseñar una lengua implica propiciar la movilización de un sujeto que realice el "agenciamiento" de nuevas formas de decir en la extranjera. 
A partir de esos presupuestos que unen LM, LE e identidad, vamos a describir y analizar los datos de esta investigación para que podamos entender cómo las futuras profesoras se evalúan como hablantes de español y si consideran que desarrollaron nuevas posiciones identitarias en el idioma.

\section{El Contexto y las Participantes de la Investigación}

Las once alumnas del último año de la carrera de Letras/ Español forman parte del primer grupo que se licenció, solamente en esa lengua extranjera, puesto que cursaron la habilitación simple, duración de 4 años. Tuvieron un plan curricular que contempló, entre otras asignaturas, las de Lengua Española (nivel 1 al 8), las Literaturas de Lengua Española 1 al 4 (durante el tercer y cuarto ańos), Práctica oral 1 y 2 y Práctica escrita 1 y 2 (primer y segundo años), Traducción ( $8^{\circ}$ semestre) y Variedades FonéticoFonológicas Hispanoamericanas ( $7{ }^{\circ}$ semestre). Además, también participaron de 400 horas de Prácticas Educativas Supervisadas y de 400 horas de Práctica como Componente Curricular (proyectos de investigación llevados a cabo en campos educativos específicos). Como ya comentamos, todas las futuras profesoras de español se formaron primeramente como hablantesusuarias, pues aprendieron el español en la propia universidad. De ellas, sólo una visitó, por un corto período, un país hispanoamericano. Las futuras profesoras de E/LE se formaron en castellano con profesores brasileños y nativos (un español, una peruana y una chilena) y utilizaron, sistemáticamente, el manual Avance $^{2}$ en los dos últimos años de la carrera, elaborado en la variedad peninsular del español. Participaron presentando comunicaciones orales y después como oyentes en el evento Seminarios de Culturas Hispánicas ${ }^{3}$ que contó con la presencia de nativos de casi todos los países hispanoamericanos y de España. Tuvieron la oportunidad, en la asignatura Variedades Fonético-Fonológicas Hispanoamericanas, de discutir, en forma teórica y práctica (análisis de películas, canciones y grabaciones diversas), el tema de la variación diatópica (geográfica) del español y recibieron la visita de algunos nativos en el aula. En ese escenario, la cuestión de tener voz en lengua espańola, es decir, una identidad lingüística en dicha lengua se puso en debate, en la jornada reflexiva, teniéndose en cuenta la relación entre lengua e identidad. Esta relación se ha establecido a través de textos del área 
de la LA, y en especial del documento de las OCEM (2006), discutidos en las clases de Prácticas Educativas Supervisadas de Español 4.

De ahí que la cuestión identitaria se consideró en cuanto a los siguientes aspectos: sentirse a gusto para comunicar lo que se piensa y desea; sentirse seguro para expresar todo lo que se quiere o necesita; no sentir ganas de desistir de hablar por no hallar las palabras adecuadas o necesarias; no tener la sensación, en el caso del español, de estar confundiéndolo con el portugués (portuñol); haber elegido una variedad lingüística del idioma que lo identifique con una zona geolectal hispánica, según la división propuesta por Moreno Fernández (2000): Espańa (castellana, andaluza y canaria) e Hispanoamericana (caribeña, centroamericana o mexicana, chilena, andina o rioplatense) y saber justificar dicha opción.

Se propuso, asimismo para la sesión, la reflexión sobre las variables que puedan haber interferido, a lo largo de la graduación, en la constitución de una nueva identidad o en el desarrollo de una voz propia en la LE. Entre esas variables se cuentan profesores nativos y brasileños; los diversos materiales didácticos y auténticos utilizados; los contactos personales o virtuales con nativos; viajes a países hispanófonos; participaciones en eventos (conferencias, congresos, seminarios) y cursos teóricos de formación (Traducción, Variedades Fonético-Fonológicas Hispanoamericanas). De las once participantes, ocho afirmaron que todavía no poseían voz propia en español, es decir, una identidad constituida en E/LE. Eso representa un porcentaje de $72,72 \%$, un número bastante revelador para el universo investigado. Las justificaciones para no haber desarrollado esa identidad se pueden percibir en algunas opiniones que enfatizan la falta de dominio del sistema lingüístico, la presencia de la interlengua (portuñol) y la falta de seguridad como algunos de los factores determinantes:

Luzza $a^{4}$ En cuanto a si tengo voz en la lengua, creo que todavía no [...] tengo dificultad en hablar, falta de vocabulario [...] de la forma correcta de conjugar los verbos, utilizar de forma correcta los pronombres que sempre tengo dificultad.

Carolina: Creo que falta aún para [que] yo [tenga] voz [...] estoy confundiendo mucho portugués con español. A veces me siento a gusto [para] hablar en español, pero en algunos momentos no. 
Jéssica: No me siento a gusto para hablar en español [aún] [...]. En las clases me sentí muy mal, creo que el nerviosismo es más a causa de eso, no tengo seguridad para hablar en español, tengo miedo de conjugar los verbos porque no tengo seguridad.

Por el discurso de las futuras profesoras de español, se percibe que para ellas existe una relación intrínseca entre el dominio formal del sistema lingüístico de la LE, desde el punto de vista de la gramática normativa, y la adquisición de una nueva voz identitaria. Así, afirman que conocer el código sería condición sine qua non para que pudiesen haberla adquirido. La inseguridad también adviene del nivel de interlengua que compromete la fluidez oral y causa nerviosismo por no poder expresar todo lo que se necesita sin tener que pensar previamente en las estructuras lingüísticas: en el léxico, en los pronombres y en los verbos. Eso puesto, Revuz (2002) reconoce que no son muchas las personas que logran obtener un buen conocimiento de una o varias lenguas extranjeras, llegando a comprender y a expresarse con exactitud en distintas situaciones comunicativas en la nueva lengua. En el caso específico de las participantes de esta investigación, el principal factor a considerarse es el hecho de aprender la lengua en la fase adulta, en situación formal en el aula, como hablantes-usuarias y como futuras profesoras. A ese respecto, opina Sílvia que es necesario seguir practicando la lengua:

Silvia: No sé si los autores están ciertos cuando hablan de la edad, pero es muy dificil. Después de las clases de Variedades [Asignatura de Variedades FonéticoFonológicas Hispano-americanas] sé que conseguimos hacer todos los fonemas, pero hay que practicar, practicar y practicar.

Reconocemos que los momentos para practicar la lengua en el aula con la exposición del sujeto aprendiz a distintas situaciones lingüísticocomunicativas no son realmente suficientes para que se sienta totalmente seguro en la LE. En una situación de aprendizaje formal como la nuestra, el contacto con la lengua queda, muchas veces, restringido al espacio educativo universitario debido a la escasez de posibilidades para interactuar en la lengua fuera del aula. Ese hecho acaba por limitar el idioma a situaciones de metalenguaje, en que lo que se pretende decir se prepara previamente, muchas veces sólo de forma memorizada: 
Clara: Me siento más a gusto [para hablar] cuando es en un contexto formal que tengo la oportunidad de prepararme para hablar y puedo [...] entrenar [...]. No me siento a gusto para hablar en contexto informal, pero en contexto formal si, me siento más a gusto.

Así, la seguridad puede venir a través de la escritura académica, por su carácter privativo, individualizado y por las inúmeras posibilidades que ofrece de reelaboración, debido a las fuentes de consulta existentes. En la oralidad, se siente más la inseguridad debido a su carácter de dinamismo e improvisación, mientras que la escrita permite la utilización del monitor, (Krashen, 1982), especie de fiscal de las producciones lingüísticas y que actúa en el aprendizaje. Ese proceso permite mayor autonomía, reflexión y reelaboración de lo que se pretende enunciar por el hablante:

Andrielly: $Y$ en relación con la oralidad y [la escritura], yo tengo más facilidad para escribir [...] en español [...] Encuentro más mi identidad escribiendo que hablando.

En lo que se refiere a la seguridad de la escritura, Revuz (2002) explica que ésta representa, por su carácter de intelectualización y racionalización, una protección contra algo que parece al mismo tiempo regresivo y transgresor, es decir, la oralidad que se caracteriza por su carácter de inmediatez e inestabilidad. En cuanto a poseer una nueva voz identitaria en la LE, en una investigación informal realizada con alumnos de Letras/Inglés y profesores que eran también alumnos de especialización, Gohn (2002) los interrogó sobre el papel que la lengua inglesa ejercía para ellos, como otra voz, en la constitución de la identidad. Así, el investigador pudo detectar que la mayor parte de las respuestas expresaba un deseo de estar en el camino adecuado para desarrollar una voz en lengua inglesa, pero reconocía que ella aún no había sido adquirida. En el primer grupo de estudiantes encuestado, de un total de 17, sólo 3 afirmaron poseer una identidad en la lengua inglesa. Ya en el segundo, de un total de 10, solamente 2 afirmaron poseerla. En nuestra sesión reflexiva, una de nuestras participantes manifiesta cierto agobio por no saber explicar quién es el "yo" que habla la LE.

Andrielly: A veces siento que no encontré mi identidad en lengua española, es como si yo fuera otra persona y me acordé de un texto de González [una de 
las consultoras del documento Orientaçöes Curriculares para o Ensino Médio - Espanhol] que habla eso: que estudiar una lengua extranjera es un otro posicionamiento delante del mundo, otra manera de ver las cosas [...] entonces yo creo que sería a veces un factor psicológico, psicolingüista, Freud, no sé. Pero es algo así, es como [si] en otra lengua no soy yo [...], los problemas lingüísticos a veces podemos solucionar [...], conjugar los verbos y todo, [aún así] no tener un posicionamiento en la otra lengua.

Como señala Andrielly, “dominar” el código lingüístico de la LE, como consideraron anteriormente Luzza, Carolina y Jéssica, no garantiza que se vaya a adquirir nuevas posiciones identitarias en la LE. De su discurso se infiere que desde nuestro contexto de investigación, la identidad, o las identidades de la LM se mantienen en la producción lingüística en español y que al sujeto se reconocerá como un brasileńo hablando espańol. Por supuesto, que existe un desplazamiento identitario cuando ese sujeto asume nuevas discursividades, muchas de ellas totalmente distintas de las que existen en su LM. En ese sentido, Celada y Rodrigues (2005, p. 9-10) aclaran que es legítimo que el brasileño le imprima al español su propia identidad:

en esa expansión por tierras brasileñas, la lengua española deberá someterse a una cierta heterogeneidad, dejándose filtrar, sin pruritos puristas, por nuevas formas de decir que resultan de la manera en que un brasileño explora su posición específica de extranjero y en el español se inscribe, pues en tal aprendizaje es, además de todo lo que hemos dicho, un errante que debe someterse al trabajo de construir materialmente un hiato entre las dos lenguas.

En esa perspectiva, Revuz (2002, p. 225) afirma que "o eu da língua estrangeira não é, jamais, completamente o da língua materna”. Por eso el contacto con la lengua y la cultura del otro es importante justamente por posibilitar esos desplazamientos identitarios. En ese sentido, Grigoletto (2003) pone de manifiesto que hablar una LE involucra desplazamientos de posiciones e, incluso, nuevas identificaciones del sujeto, y Cavalheiro (2007, p. 44) corrobora que "o desejo de falar a língua do outro, de ser um outro, parece uma tentativa de evocar o eu estrangeiro, o próprio estranhamento".

Como ya señalamos, los sujetos de esta investigación están todo el tiempo posicionados entre esas dos lenguas: el portugués brasileño y el español. La presencia de la primera de ellas es tan fuerte y significativa, en la producción lingüística del E/LE, que a veces la sensación es de que, lo que 
se produce, es una mera traducción de su lengua para la lengua del otro. Andrielly considera ese hecho algo negativo y anhela adquirir cadencia, ritmo y entonación propios de la LE, además de elegir adecuadamente una variedad diatópica, como condiciones para obtener una voz propia en la LE, para expresarse adecuadamente en ella. En esa búsqueda, cree que estar inmersa en la cultura extranjera sería una posible solución:

Andrielly: Yo creo que la entonación forma parte del acento, porque a veces cuando hablo español es como si yo [...] estuviera pasando del portugués al español. Me siento así, hablando las palabras en español, la pronunciación en español, pero en el ritmo [...] brasileño. Y a veces en mi casa yo intento, cuando preparo lo que voy a decir [para una] presentación, [...] intento dar una entonación distinta, un ritmo a veces más rápido o unos altos y bajos para salir un poquito de eso. Es eso que me gustaría tener [...], hablar así con más ritmo ¿sabe? Por eso creo que sería bueno ir a un país [hispanohablante], [...] para volver hablando con más entonación de acuerdo con la variedad [geolectal] que yo he elegido.

Con relación a la traducción, Cavallari (2008, p. 4) explica que se puede echar mano de ella como un intento interpretativo, un intento de posicionarse como sujeto en una realidad desconocida y que no domina: "[é] o funcionamento da LM no sujeito ou, até mesmo, o funcionamento da LE marcada pela LM, que direciona a interpretação do aluno que parece estar em busca de uma tradução". En nuestro contexto (Goiano), lo que no podemos dejar de considerar es qué la inmersión en un país hispanófono, para la inmensa mayoría de los estudiantes, suena como una utopía, una vez que las condiciones financieras son precarias. Siendo más bien realistas, debemos pensar en formas creativas y auténticas de contacto con la lengua, desde nuestro país, principalmente utilizando las nuevas formas de la tecnología de la comunicación.

En cuanto al acento brasileño al hablar español, en proceso formal de aprendizaje es algo que no se debe rechazar, puesto que, se relaciona con la identidad lingüística brasileña. Para Fanjul (2004, p. 180), el brasileño tiene el derecho de hablar español como brasileño que es: "falar espanhol como um brasileiro não é somente um direito lingüístico inalienável do brasileiro, mas também que essa fala é, para quem pesquisa sobre a língua espanhola, mais uma fonte de aprendizagem sobre essa língua. Y Revuz (2002, p. 222), 
hace hincapié en que no es precisamente una incapacidad funcional de producir los sonidos de la nueva lengua, "trata-se mais de uma incapacidade de jogar de modo diferente com a acentuação, com sons, ritmos e entoações, mesmo conhecidas".

\section{Consideraciones finales}

Al pensar en el proceso de formación universitaria del futuro profesor de E/LE en Brasil, principalmente en la fase adulta y en situación formal de aprendizaje en el aula, es necesario considerar que estudiar una nueva lengua, proyectarse en ella, revelarse como su sujeto, adquirir una voz propia, demostrar quiénes somos, lo qué pensamos y queremos, es un largo y persistente recorrido que no se llegó a enfrentar por el grupo investigado. Las opiniones aquí presentadas sintetizaron la preocupación primordial del grupo en dominar el sistema lingüístico y también algunas de las destrezas lingüísticas, especialmente la expresión oral y la expresión escrita. Todas esas cuestiones se sobrepusieron a la cuestión identitaria que se redujo a la necesidad de mantener un mayor contacto con la lengua, como podemos observar en el discurso de Luzza:

Luzza: Tener contacto y practicar, tenemos que practicar, no podemos lograr la competencia comunicativa, tener voz en la lengua si no la utilizamos, si no la practicamos y si no tenemos contacto con ella. Entonces [...] yo creo que es: hablar, oir y practicar [...].

Entendemos que sólo cuatro años de contacto con la lengua en la licenciatura es un período verdaderamente corto para que se cumplan todas las demandas de formación del hablante-usuario y profesional docente de esa lengua. Sin embargo, para nosotros profesores queda claro que debemos intensificar las discusiones respecto a las cuestiones que involucran LM, LE e identidad desde el ingreso del estudiante en la carrera. De eso no debe hacerse cargo solamente las clases de Prácticas Educativas Supervisadas puesto que es un desafío a ser enfrentado por todos los profesores de esta licenciatura. Eso se hace necesario para que el sujeto aprendiz entienda mejor su relación con la LM y las posibles relaciones que podrá constituir en la LE. Para Celada y Rodrigues (2005, p. 9): "La lengua española debería mostrar los 
saberes y caminos por los cuales un sujeto puede transitar, des/reterritorializándose a partir de la materna [...]". En esa perspectiva, tratándose de esas dos lenguas tan próximas, el portugués brasileño y el español, el aprendizaje de ésta última podrá hacerse de forma más realista y exitosa.

\section{Notas}

1. Este documento se publicó por ocasión de la aprobación de la Ley Federal no 11.161/05 que hace obligatoria la oferta de la lengua española en la educación de nivel medio en Brasil a partir de agosto de este año.

2. Se trata del libro de texto Avance: Curso de Español, de las autoras Concha Moreno, Victoria Moreno y Piedad Zurita, publicado por la Sociedad General Española de Librería (SGEL). Este manual pasó a ser utilizado en al graduación en Letras/ Español en el 2006 porque adopta una postura intercultural en el tratamiento de algunas temáticas y contenidos socioculturales.

3. Ese evento se llevó a cabo en el segundo semestre de 2006, de agosto a diciembre. En un primer momento, había una mesa redonda con debates entre nativos de origen hispánico. En un segundo momento, los alumnos presentaban seminarios con las investigaciones realizadas sobre dichos países.

4. Las participantes se identifican por seudónimos para resguardar sus identidades.

\section{Referencias}

BUGEL, T. Aspectos ideológicos y culturales de la enseñanza actual del español como lengua extranjera en la ciudad de San Pablo - Brasil. In: Actas del XI Congreso Internacional de ASELE. Zaragoza: sept. 2000, p. 239-246. Disponível em: <http://cvc.cervantes.es/ensenanza/biblioteca_ele/asele/ pdf/11/11_0239.pdf>. Acesso em: 13 maio 2010.

BUTLER, J. Corpos que pesam: sobre os limites discursivos do sexo. In: LOURO, G. L. (Org.). O corpo educado. Pedagogias da sexualidade. Belo Horizonte: Autêntica, 1999. p. 25-39.

CAVALHEIRO, A. L. P. Uma mirada pelo prisma da identidade... In: CAVALHEIRO, A. L. P.; IRALA, V. B. O Imaginário da Lingua Espanhola. Pelotas: Educat, 2007. 
CAVALLARI, J. S. O conflitante encontro da lingua materna com a lingua estrangeira. Disponível em: <http://www.unicamp.br/iel/site/alunos/publicacoes/textos/c00015.htm>. p. 1-7. Acesso em: 15 out. 2009.

CELADA, M. T. Uma lingua singularmente estrangeira. O espanhol para o brasileiro. 2002. Tese (Doutorado em Linguística) - IEL/Unicamp, Departamento de Linguística, Campinas, SP, 220f, 2002.

CELADA, M. T.; RODRIGUES, F. S. C. El español en Brasil: actualidad y memoria. Real Instituto Elcano de Estudios Internacionales y Estratégicos. Sección "Lengua y Cultura”, p. 1-10, 2005. Disponível em: <http://www.lai. at/wissenschaft/lehrgang/semester/ss2005/rv/files/celadayrodrigues. 2005. pdf>. Acesso em: 13 maio 2010.

FANJUL, A. P. Português brasileiro, espanhol de... onde? Analogias incertas. Letras \& Letras. Uberlândia 20(1), jan./jun., 2004, p. 165-183.

FERNÁNDEZ, F. M. ¿Qué español enseñar? Madrid: Arco/Libros, 2000.

GIDDENS, A. As conseqüências da modernidade. Tradução de Raul Fiker. São Paulo: UNESP, 1991.

GOHN, C. A. A tarefa de desestrangeirizar a língua inglesa e o processo de chegar a ter sua própria voz em uma segunda língua. Anais do VI Congresso Brasileiro de Lingüistica Aplicada, Cd-Rom, Belo Horizonte, UFMG, 2002.

GRIGOLETTO, M. Representação, identidade e aprendizagem de língua estrangeira. In: CORACINI, M. J. (Org.). Identidade e discurso. Discursos sobre e na sala de aula, Campinas, SP: Ed. Da Unicamp/Chapecó, RS: Argos Ed. Universitária, 2003. p. 223-235.

HALL, S. Quem precisa da identidade? In: SILVA, T. T. da (Org.). Identidade e diferença: A perspectiva dos Estudos Culturais, Petrópolis, Vozes, 2000.

HALL, S. A Identidade cultural na pós-modernidade. Tradução de Tomaz Tadeu da Silva; Guaracira Lopes Louro. 10 ed. Rio de Janeiro: DP \& A, 2005.

KRASHEN, S. D. Principles and Practice in Second Language Acquisition. Oxford: Pergamon Press, 1982. 
KULIKOWSKI, M. Z. M; GONZÁLEZ, N. T. M. Español para brasileños. Sobre por dónde determinar la justa medida de una cercanía. In: Anuario Brasileño de Estudios Hispánicos, IX, Brasília, p. 11-19, 1999.

MINISTÉRIO DA EDUCAÇÃO. Secretaria de Educação Básica. Orientaçôes Curriculares para o ensino médio. Linguagem, códigos e suas tecnologias, Cap. 4, Conhecimentos de Espanhol, Brasília, v. 1, p. 125-164, 2006.

NEVES, M. S. O processo identificatório na relação professor-aluno na aprendizagem de língua estrangeira. In: MAGALHÁES, I.; CORACINI, M. J.; GRIGOLETTO, M. (Org.). Práticas identitárias: língua e discurso. São Carlos: Claraluz, 2006. p. 118-139.

REVUZ, C. A. A língua estrangeira entre o desejo de um outro lugar e o risco do exílio. In: SIGNORINI, I. (Org.), Lingua(gem) e identidade. São Paulo: Mercado de Letras, 2002. p. 213-230.

SERRANI-INFANTE, S. M. Identidade e segundas línguas: as identificaçôes no discurso. In: SIGNORINI, I. (Org.). Lingua(gem) e Identidade. Campinas, SP: Mercado de Letras, São Paulo, Fapesp, 2002. p. 231-264.

SILVA, T. T. Da. A produção social da identidade e da diferença. In: SILVA, T. T. da (Org.). Identidade e diferença: A perspectiva dos Estudos Culturais. Petrópolis: Vozes, 2000. p. 73-102.

SOUZA, L. F. A. de. Representaçóes de língua, aprendizagem e identidade nacional no dizer de falantes de espanhol. Lingua, Literatura \& Ensino, Maio, v. II, p. 1-8, 2007. Disponível em: <http://www.iel.unicamp.br/revista/index.php/lle/issue/view/1>. Acesso em: 15 jan. 2009.

WOODWARD, J. Identidade e diferença: uma introdução teórica e conceitual. In: SILVA, T. T. da (Org.). Identidade e diferença: a perspectiva dos estudos culturais. Petrópolis: Vozes, 2000. p. 7-72.

Recebido em: 11 mar. 2010

Aceito em: 6 maio 2010 